\title{
ANALISIS MENENTUKAN REKOMENDASI PENYEJUK UDARA YANG TEPAT MENGGUNAKAN METODE MOORA
}

\author{
Saghifa Fitriana \\ Jurusan Sistem Informasi,STMIK Nusa Mandiri Jakarta \\ e-mail: saghifa.sff@nusamandiri.ac.id
}

\begin{abstract}
Based on BMKG monitoring in 20 weather and climate stations, temperatures in various parts of Indonesia range from 34 to 37.5 degrees Celsius. So that many Indonesians choose to use the air conditioner. The number of choices starting from the AC brand, the price and quality offered make consumers become selective in choosing the AC to be purchased. This is of course adapted to the abilities and needs of each consumer. Fhery uses calculations using the Fuzzy SAW method (Simple Additive Weighting) in the Recommendation for Selecting Air Conditioning Devices with AC Age Durability criteria, Damage rate, Electricity Consumption, Technology used and Price [3]. In this study will make a Decision Support System using the MOORA method. Because it is one of the DSS methods that can determine the objectives of the criteria with a good level of selection where the criteria can be beneficial (benefit) or not profitable (cost). By using the criteria based on AC lifespan, capacity, electricity consumption, technology used and price, the alternative $y_{2}^{*}$ choice is AC SHARP AH-A5UCY brand with a value of optimization of 4.6985 indicating that the value is the largest alternative value of the alternative value other.
\end{abstract}

Keywords - AC, AC Specifications, MCDM, MOORA Method.

Abstrak- Berdasarkan pemantauan BMKG di 20 stasiun cuaca dan iklim, suhu di berbagai wilayah Indonesia berkisar antara 34 hingga 37,5 derajat Celsius. Sehingga membuat masyarakat indonesia banyak yang memilih untuk menggunakan pendingin/penyejuk udara tersebut. Banyaknya pilihan mulai dari merk $\mathrm{AC}$, harga dan Kualitas yang ditawarkan membuat konsumen menjadi selektif dalam memilih AC yang akan dibeli. Hal tersebut tentunya disesuaikan dengan kemampuan dan kebutuhan masing-masing konsumen. Fhery menggunakan perhitungan dengan metode Fuzzy SAW(Simple Additive Weighting) dalam Rekomendasi Pemilihan Perangkat Penyejuk Udara dengan kriteria Daya Tahan Umur AC, tingkat Kerusakan, Konsumsi Listrik, Teknologi yang digunakan dan Harga[3]. Dalam penelitian ini akan membuat Sistem Pendukung Keputusan dengan metode MOORA. Karena merupakan salah satu metode DSS yang dapat menentukan tujuan kriteria dengan tingkat penyeleksian yang baik dimana kriteria dapat bernilai menguntungkan(benefit) atau yang tidak menguntungkan(cost). Dengan menggunakan kriteria berdasarkan Daya tahan umur AC, Kapasitas, Konsumsi Listrik, Teknologi yang digunakan dan Harga maka menghasilkan pilihan alternatif $y_{2}^{*}$ yaitu AC Merk SHARP AH-A5UCY dengan Nilai Optimasi sebesar 4,6985 menunjukan bahwa nilai tersebut adalah nilai alternatif terbesar dari nilai alternatif yang lain.

\section{Kata Kunci : AC, Spesifikasi AC, MCDM, Metode MOORA}

\section{A. PENDAHULUAN}

Maraknya perusahaan yang berkembang dibidang IT secara online salah satunya berbentuk Market Place yang sekarang ini banyak dirasakan manfaatnya oleh masyarakat. Masyarakat merasa sangat dipermudah dengan adanya pelayanan yang disediakan oleh perusahaan market place tersebut untuk berbelanja secara online, tidak perlu datang ke tokonya langsung. Cukup dirumah saja sudah mendapatkan informasi yang lengkap dari admin/cs toko tersebut yang dapat dihubungi melalui chat online. Calon pembeli diberikan fasilitas pelayanan berupa chatting langsung dengan bagian admin/cs untuk menanyakan secara detail mengenai barang yang akan dibeli.

Barang-barang yang dijual dalam market place tersebut pun bermacam-macam, mulai dari bahan kebutuhan sehari-hari, alat-alat rumah tangga, elektronik, pakaian, makanan, minuman, dll. Salah satu kebutuhan penting 
dalam Rumah Tangga yaitu alat elektronik seperti AC(Air Conditioner).

Perubahan iklim didunia saat ini menjadi salah satu faktor Masyarakat Indonesia untuk menggunakan AC. Berbagai wilayah di Indonesia menurut pantauan dari BMKG mengalami suhu antara 34 sampai 37,5 derajat Celcius. Berdasarkan data tersebut, terdeteksi bahwa suhu yang tinggi berada di wilayah selatan khatulistiwa. Suhu yanag tinggi pun sama terdeteksi seperti yang dipantau oleh Stasiun Meteorologi Jatiwangi terpantau bahwa suhu di Majalengkamencapai 37,4 derajat Celsius. Hal yang sama terjadi juga di Nusa tenggara berdasar panatauan dari stasiun meteorologi Gewayantan yaitu suhu mencapai 35,2 derajat Celsius. Sedangkan Di Kota Jakarta sebagai kota metropolitan yang padat penduduk serta banyaknya pabrik, terpantau oleh stasiun meteorologi Kemayoran, suhunya mencapai 34,2 derajat Celsius[1]. Hal tersebutlah yang melatarbelakangi banyaknya jumlah pengguna AC. Tentu dengan seiring berkembangnya pertumbuhan ekonomi Masyarakat Indonesia yang semakin meningkat dan sejahtera tidak menutup kemungkinan akan semakin bertambah peminat AC di Indonesia, bahkan mungkin bisa menjadi salah satu Kebutuhan Pokok setiap rumah. Salah satu teknologi AC yang diminati yaitu teknologi inverter. Berdasarakan penjelasan dari Direktur Konservasi Energi pada Direktorat Jenderal Energi Baru ESDM yaitu Bapak HariyantoAC yang menggunakan inverter saat ini di Indonesia diperkirakan sejumlah 9 persen selebihnya belum menggunakan teknologi inverter[2].

Fhery menggunakan perhitungan dengan metode Fuzzy SAW(Simple Additive Weighting) dalam Rekomendasi Pemilihan Perangkat Penyejuk Udara dengan kriteria Daya Tahan Umur AC, tingkat Kerusakan, Konsumsi Listrik, Teknologi yang digunakan dan Harga[3]. Aprina dkk menggunakan basis data Fuzzy Tahani untuk mencari nilai dari setiap jenis mesin cuci menurut beberapa kriteria yaitu Harga, Pemakaian daya, Kapasitas dan Berat[4]. Nur dan Toni dalam penelitiannya untuk menentukan kualitas mesin cuci terbaik yang sesuai dengan kebutuhan konsumen berdasarkan pada beberapa kriteria seperti Harga, Jenis Tabung, Merk,Kapasitas, Kecepatan, Konsumsi, Berat, Panjang, Lebar, Tinggi, Bukaan Pintu, Garansi[5]. Biasanya masing-masing orang mempunyai kriteria dalam menentukan barang yang akan dibeli, terlebih jika barang tersebut tergolong mahal dan akan digunakan dalam jangka panjang. Sistem Pendukung Keputusan(SPK) menjadi penyelesaian yang dapat digunakan untuk membuat keputusan dalam menentukan barang yang akan dibeli. Metode Sistem Pendukung Keputusan yang akan digunakan yaitu MCDM(Multi Criteria Decision Making) dengan menggunakan Metode MOORA(Multi-Objective Optimization on the basis of Ratio Analysis).

\section{B. TINJAUAN PUSTAKA}

1. Penggunaan AC

Air Conditioner atau AC sering juga disebut dengan penyejuk/pendingin ruangan menjadi salah satu kebutuhan dalam Peralatan Rumah Tangga. Selain dikarenakan perubahan iklim, faktor lain adalah kebiasaan dalam keluarganya. Biasanya pengguna penyejuk ruangan ini adalah masyarakat dengan golongan ekonomi menengah keatas. Ada faktor lain juga yaitu iklim masing-masing wilayah, misalnya seperti di kota-kota besar yang padat penduduk. Banyak rumah yang menggunakan $\mathrm{AC}$ meskipun rumah dengan ukuran kecil.

Untuk menentukan AC yang tepat disesuaikan dengan Kapasitas AC(Paard Kracht atau PK) dan kapasitas Daya Listrik masing-masing Rumah. Istilah Kapasitas/PK AC sering juga disebut sebagai horsepower atau tenaga dari AC. Rumus yang digunakan untuk menghitung PK/Kapasitas AC yang diperlukan :

Luas Ruangan $\left(\mathrm{m}^{2}\right)$ × 500 atau Lebar $\times$ Panjang $\times 500$

Kalkulasi ini berasumsi jika tinggi ruangan antara $2.50-3$ meter.

Bagan Konversi PK :

$1 / 2 \mathrm{PK}=5000 \mathrm{Btu} / \mathrm{h}$ (ukuran ruangan $10 \mathrm{~m}^{2}$ )

$3 / 4 \mathrm{PK}=7000 \mathrm{Btu} / \mathrm{h}$ (ukuran ruangan $14 \mathrm{~m}^{2}$ )

$1 \mathrm{PK}=9000 \mathrm{Btu} / \mathrm{h}$ (ukuran ruangan $18 \mathrm{~m}^{2}$ )

$1 \frac{1}{2} \mathrm{PK}=12000 \mathrm{Btu} / \mathrm{h}$ (ukuran ruangan $24 \mathrm{~m}^{2}$ ) 
$2 \mathrm{PK}=18000 \mathrm{Btu} / \mathrm{h}$ (ukuran ruangan $36 \mathrm{~m}^{2}$ ) Berikut Jenis-jenis AC berdasarkan Kapasitas Daya Listrik Rumah[6] :

Tabel 2.1. Jenin-jenis AC

\begin{tabular}{|c|c|c|c|}
\hline $\begin{array}{l}\text { Jenis } \text { PK } \\
\text { AC }\end{array}$ & $\begin{array}{l}\text { AC } \\
\text { Standard }\end{array}$ & $\begin{array}{l}\text { AC } \\
\text { Low } \\
\text { Watt }\end{array}$ & $\begin{array}{l}\text { AC } \\
\text { Inventer }\end{array}$ \\
\hline $\mathrm{AC} 1 / 2 \mathrm{PK}$ & 400 Watt & $\begin{array}{l}320 \\
\text { Watt }\end{array}$ & \\
\hline $\mathrm{AC} 3 / 4 \mathrm{PK}$ & 600 Watt & $\begin{array}{l}530 \\
\text { Watt }\end{array}$ & \\
\hline $\mathrm{AC} 1 \mathrm{PK}$ & 840 Watt & $\begin{array}{l}660 \\
\text { Watt }\end{array}$ & $\begin{array}{l}225-920 \\
\text { Watt }\end{array}$ \\
\hline $\mathrm{AC} 1.5 \mathrm{PK}$ & $\begin{array}{l}1170 \\
\text { Watt }\end{array}$ & & $\begin{array}{l}270- \\
1070 \\
\text { Watt }\end{array}$ \\
\hline $\mathrm{AC} 2 \mathrm{PK}$ & $\begin{array}{l}1920 \\
\text { Watt }\end{array}$ & & $\begin{array}{l}300- \\
1710 \\
\text { Watt }\end{array}$ \\
\hline $\mathrm{AC} 2.5 \mathrm{PK}$ & $\begin{array}{l}2570 \\
\text { Watt }\end{array}$ & & $\begin{array}{l}350- \\
2220 \\
\text { Watt }\end{array}$ \\
\hline
\end{tabular}

2. Sistem Pendukung Keputusan

Turban, dkk dalam Samuel menjelaskan bahwa Decision Support System(Sistem Pendukung Keputusan) merupakan sistem informasi level manajemen dari suatu organisasi dengan mengkombinasikan data dan model analisis canggih atau peralatan data analisis untuk mendukung pengambilan keputusan-keputusan yang semi terstruktur dan tidak terstruktur[7].

Karakteristik dari Sistem Pendukung Keputusan yaitu[8] :

a. Sebagai pendukung proses pengambilan keputusan suatu organisasi atau perusahaan.

b. Interface manusia/mesin sebagai pemegang kontrol proses pengambilan keputusan.

c. Sebagai Pendukung pengambilan keputusan untuk membahas masalah terstruktur, semi terstruktur dan keputusan yang saling berinteraksi.

d. Menggunakan kapasitas dialog dalam memperoleh informasi yang sesuai dengan keputusan. e. Memiliki subsistem yang terintegrasi dengan baik sehingga dapat berfungsi sebagai kesatuan sistem.

f. Memiliki data dan model sebagai komponen utama.

Menurut Simon dalam Dicky ada tiga fase dalam proses pengambilan keputusan diantaranya sebagai berikut[8]:

1. Intelligence

Tahap ini akan melakukan proses penelusuran dan pendeteksian dari ruang lingkup problematika dengan cara mengolah pengenalan/inisiasi masalah. Maka akan menghasilkan data yang kemudian akan diproses dan diuji untuk menghasilkan identifikasi masalah.

\section{Design}

Langkah ini akan melakukan proses untuk menemukan, mengembangkan dan menganalisis alternatif tindakan yang bisa dilakukan. Dalam hal ini yaitu kelayakan solusi.

3. Choice

Proses terakhir yaitu memilih salah satu diantara berbagai alternatif tindakan yang dimungkinkan dapat dijalankan. Kemudian dari hasil pemilihan alternatif tersebut akan diimplementasikan dalam proses pengambilan keputusan.

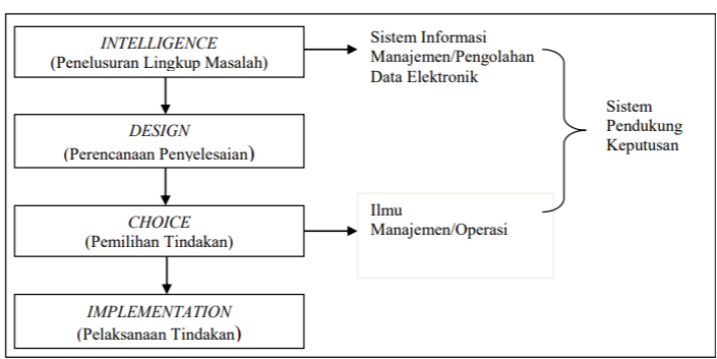

Gambar 2.1 Tahap Proses

Pengambilan Keputusan

3. MCDM(Multi Criteria Decision Making)

Multi Criteria Decision Making (MCDM) adalah salah satu metode yang sering kali digunakan dalam menentukankeputusan yang akan diambil. Tujuan MCDM adalah penentuan dari pengambil keputusan dalam membuat keputusan padapengambilan alternatif yang terbaik dari banyaknyaalternatif 
bersifat eksklusif yang saling menguntungkan yang melatarbelakangi performansi umum dari berbagai macam kriteria (atau atribut) [9].

Ada empat langkah pengambilan keputusan dalam MCDM [10] meliputi:
a. Identifikasi Masalah
b. Menyusun Preferensi
c. Mengevaluasi Alternatif
d. Menentukan Alternatif Terbaik

\section{Metode MOORA}

Brauers dan Zavadkas yang telah memperkenalkan Metode MOORA(2006). Metode ini tergolong metode baru yangpertama kali digunakan oleh Brauers(2003) dalam suatu pengambilan keputusan dengan multi-kriteria. Dengan tingkat fleksibilitas yang tinggi, Metode MOORA memiliki kemudahan untuk dipahami.Dalam hal ini yaitu untuk mengelompokkan bagian subjektif dari suatu proses evaluasi kedalam kriteria bobot keputusan dengan beberapa pilihan atribut dalam pengambilan keputusan[12]. Dan Metode ini dapat menentukan tjuan dari beberapa kriteria bernilai menguntungkan dan tidak menguntungkan yang bertentangan sehingga dapat disimpulkan bahwa metode ini memiliki tingkat selektifitas yang baik.

\section{METODE PENELITIAN}

1. Tahapan Penelitian :

Dalam penelitian ini dilakukan beberapa tahapan sebagai berikut :

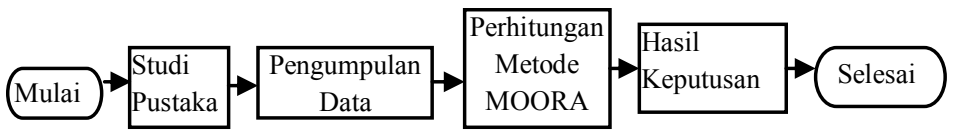

Gambar 3.1. Tahapan Penelitian

Pada tahap studi pustaka akan membahas penelitian sebelumya yang serupa dengan penelitian ini. Mencari penyelesaian dalam hal ini yaitu menentukan keputusan dari beberapa pilihan alternatif yang ada menggunakan metode yang ada dalam SPK. Kemudian selanjutnya akan dilakukan pengumpulan data sebagai hasil dari pencarian data yang dibutuhkan. Langkah berikutnya yaitu proses perhitungan dengan metode MOORA yang akan dijelaskan secara detail perhitungan pencarian keputusan dengan menggunakan rumus-rumus yang ada di metode MOORA supaya menghasilkan solusi atau keputusan yang direkomendasikan. Dalam hal ini yaitu menentukan produk AC terbaik berdasarkan beberapa kriteria.

\section{Pengumpulan Data}

AC yang banyak digunakan di indonesia ada beberapa merk. Data tersebut didapat dari beberapa sumber yang dilakukan melaluipencarian di beberapa situs masingmasingmerk $A C$ untuk mendapatkan detail spesifikasi dari unit AC yang diambil secara acak berdasar produk yang paling banyak dibeli oleh konsumen Indonesia.Berikut data merk AC yang banyak digunakan di Indonesia berdasarkan situs web dari masing-masing merk AC :

Tabel 2. Tabel Pengumpulan Data

\begin{tabular}{|l|l|l|l|l|l|l|}
\hline Kode & Merk AC & $\begin{array}{l}\text { Daya } \\
\text { Tahan } \\
\text { Umur } \\
\text { AC }\end{array}$ & Kapasitas & $\begin{array}{l}\text { Konsumsi } \\
\text { Listrik }\end{array}$ & $\begin{array}{l}\text { Teknologi } \\
\text { yang } \\
\text { digunakan }\end{array}$ & Harga \\
\hline A1 & LG T05NL & $\begin{array}{l}10 \\
\text { Tahun }\end{array}$ & $1 / 2$ PK & 435 Watt & Inverter & $\begin{array}{l}\text { Rp } \\
2.785 .000\end{array}$ \\
\hline A2 & SHARP AH-A5UCY & $\begin{array}{l}10 \\
\text { Tahun }\end{array}$ & $1 / 2$ PK & 350 Watt & $\begin{array}{l}\text { Turbo } \\
\text { Cooling, } \\
\text { Self } \\
\text { diagnosis, } \\
\text { Ex-fan } \\
\text { function }\end{array}$ & $\begin{array}{l}\text { Rp } \\
2.450 .000\end{array}$ \\
\hline A3 & \begin{tabular}{llllll|} 
PANASONIC CS CU- \\
YN 5 TKJ
\end{tabular} & $\begin{array}{l}10 \\
\text { Tahun }\end{array}$ & $1 / 2$ PK & 410 Watt & Low Watt & $\begin{array}{l}\text { Rp } \\
2.950 .000\end{array}$ \\
\hline A4 & $\begin{array}{l}\text { SAMSUNG } \\
\text { AR05NRFLWWNSE }\end{array}$ & $\begin{array}{l}10 \\
\text { Tahun }\end{array}$ & $1 / 2$ PK & 400 Watt & Fast Cooling & $\begin{array}{l}\text { Rp } \\
2.550 .000\end{array}$ \\
\hline A5 & $\begin{array}{l}\text { DAIKIN } \\
\text { FTKQ15SVM4 }\end{array}$ & $\begin{array}{l}10 \\
\text { Tahun }\end{array}$ & $1 / 2$ PK & 310 Watt & $\begin{array}{l}\text { Flash } \\
\text { Inverter }\end{array}$ & $\begin{array}{l}\text { Rp } \\
4.150 .000\end{array}$ \\
\hline A6 & MITSUBISHI & $\begin{array}{l}10 \\
\text { Tahun }\end{array}$ & $1 / 2$ PK & 435 Watt & Inverter & $\begin{array}{l}\text { Rp } \\
3.060 .000\end{array}$ \\
\hline
\end{tabular}

3. Perhitungan Metode MOORA

Langkah penyelesaian :

a. Memasukan nilai kriteria

Membuat tujuan sebagai identifikasi atribut evaluasi yang terkait dan menginputkan nilai kriteria pada suatu alternatif dimana nilai tersebut nantinya akan diproses dan hasilnya akan menjadi sebuah keputusan.

b. Membuat Matrix Keputusan

Mewakilkan semua informasi yang tersedia untuk setiap atribut dalam bentuk matrix keputusan. Data pada persamaan [MOO01] mempresentasikan sebuah matrix $\mathrm{x}_{\mathrm{m} \mathrm{xn}}$. Dimana $\mathrm{x}_{\mathrm{ij}}$ adalah pengukuran kinerja dari alternatif $\mathrm{i}^{\text {th }}$ pada atribut $\mathrm{j}^{\text {th }}, \mathrm{m}$ adalah jumlah alternatif dan $\mathrm{n}$ adalah jumlah atribut/kriteria. Kemudian sistem ratio dikembangkan dimana setiap kinerja dari sebuah alternatif pada sebuah atribut dibandingkan dengan penyebut yang 
merupakan wakil untuk semua alternatif dan atribut tersebut. Berikut ini adalah proses merubah nilai kriteria menjadi sebuah matriks keputusan :

$$
x=\left[\begin{array}{ccccc}
x_{11} & \cdots & x_{1 i} & \cdots & x_{1 n} \\
\vdots & \ddots & \vdots & \ddots & \vdots \\
x_{j 1} & \cdots & x_{i j} & \cdots & x_{j n} \\
\vdots & \ddots & \vdots & \ddots & \vdots \\
x_{m 1} & \cdots & x_{m i} & \cdots & x_{m n}
\end{array}\right]
$$

...[MOO-01]

Keterangan :

$\mathrm{x}_{\mathrm{ij}}=$ Respon alternatif $\mathrm{j}$ pada kriteria $\mathrm{i}$

$\mathrm{i}=1,2,3, \ldots, \mathrm{n}$ adalah nomor urutan

atribut atau kriteria

j $=1,2,3, \ldots$, n adalah nomor urutan

alternatif

$X=$ Matriks Keputusan

c. Matrix Normalisasi

Normalisasi bertujuan untuk menyatukan setiap element matriks sehingga element pada matriks memiliki nilai yang seragam. Brauers menyimpulkan bahwa untuk penyebut, pilihan terbaik adalah akar kuadrat dari jumlah kuadrat dari setiap alternatif per atribut(Brauers 2008). Rasio ini dapat dinyatakan sebagai berikut :

$X^{*}{ }_{i j}=\frac{x_{i j}}{\sqrt{\left[\sum_{j=1}^{m} x_{i j}^{2}\right]}}$

....[MOO-02]

Keterangan :

$\mathrm{x}_{\mathrm{ij}}=$ Matriks alternatif $\mathrm{j}$ pada kriteria $\mathrm{i}$

$\mathrm{i}=1,2,3, \ldots, \mathrm{n}$ adalah nomor urutan

atribut atau kriteria

j $=1,2,3, \ldots, \mathrm{n}$ adalah nomor urutan

alternatif

$X^{*}{ }_{i j}=$ Matriks Normalisasi alternatif $\mathrm{j}$

pada kriteria i

d. Menghitung Nilai Optimasi

1) Jika atribut atau kriteria pada masing-masing alternatif tidak diberikan nilai bobot.Ukuran yang dinormalisasi ditambahkan dalam kasus maksimasi(untuk atribut yang menguntungkan) dan dikurangi dalam minimasi(untuk atribut yang tidak menguntungkan) atau dengan kata lain mengurangi nilai maximum dan minimum pada setiap baris untuk mendapatkan rangking pada setiap baris, jika dirumuskan maka :

$$
\begin{aligned}
& y_{j}^{*}=\sum_{i=1}^{i=g} x_{i j}^{*}- \\
& \sum_{i=g+1}^{i=n} x_{i j}^{*} \ldots .[\mathrm{MOO}-03]
\end{aligned}
$$

Keterangan :

$\mathrm{i}=1,2,3, \ldots, \mathrm{g}$ adalah atribut atau kriteria dengan status maximized $\mathrm{j}=\mathrm{g}+1, \mathrm{~g}+2, \mathrm{~g}+3, \ldots, \mathrm{n}$ adalah atribut atau kriteria dengan status minimized

$y_{j}^{*}=$ Matriks Normalisasi max-min alternatif $j$.

2) Jika masing-masing alternatif pada kriteria diberikan nilai bobot kepentingan. Maka Pemberian nilai bobot pada kriteria yaitu dengan ketentuan nilai bobot jenis kriteria maximum lebih besar dari nilai bobot jenis kriteria minimum. Untuk menandakan bahwa sebuah atribut lebih penting, bisa dikalikan dengan bobot yang sesuai (koefisien signifikasi) (Brauers et al.2009 dalam Ozcelik, 2014).

Berikut rumus menghitung nilai Optimasi Multiobjektif MOORA, perkalian bobot kriteria terhadap nilai atribut maximum dikurang perkalian bobot kriteria terhadap nilai atribut minimum, jika dirumuskan maka :

$y_{i}=\sum_{j=1}^{g} w_{j} x_{i j}^{*}-$

$\sum_{j=g+1}^{n} w_{j} x_{i j}^{*} \ldots . .[\mathrm{MOO}-04]$

Keterangan :

$\mathrm{i}=1,2,3, \ldots, \mathrm{g}$ adalah atribut atau kriteria degan status maximized

$\mathrm{j}=\mathrm{g}+1, \mathrm{~g}+2, \mathrm{~g}+3, \ldots, \mathrm{n}$ adalah atribut atau kriteria dengan status minimized

$w_{j}=$ bobot terhadap alternatif $\mathrm{j}$

$y_{j}^{*}=$ Nilai penilaian yang sudaha dinormalisasi dari alternatif $\mathrm{j}$ terhadap semua atribut.

e. Perangkingan

Nilai dapat menjadi positif atau negatif tergantung dari total maksimal(atribut 
yang menguntungkan) dalam matriks keputusan. Sebuah urutan peringkat dari menunjukkan pilihan terakhir.Dapat disimpulkan bahwa nilai yang tertinggi adalah alternatif yang terbaik dan sebaliknya nilai terendah adalah untuk alternatif terburuk.

Berdasarkan perhitungan dengan Metode MOORA, menghasilkan :

a. Pemilihan alternatif terbaik yang sesuai dengan permasalahan yang sedang dicari solusinya dapat diambil berdasarkan nilai yang tertinggi. Karena alternatif dengan nilai yang tertinggi merupakan alternatif terbaik.

b. Apabila nilai dari sebuah alternatif adalah nilai terendah maka alternatif tersebut adalah alternatif terburuk.

\section{HASIL DAN PEMBAHASAN}

1. Perhitungan Metode MOORA

Membuat Matrix of Responses membuat atribut/kriteria

Tabel 3. Kriteria dan Pembobotan

\begin{tabular}{|l|l|l|l|}
\hline $\begin{array}{l}\text { Kode } \\
\text { Kriteria }\end{array}$ & Nama Kriteria & Tipe & Bobot \\
\hline C1 & $\begin{array}{l}\text { Daya Tahan Umur } \\
\text { AC }\end{array}$ & + & 2,9 \\
\hline C2 & Kapasitas & - & 1,7 \\
\hline C3 & Konsumsi Listrik & - & 1,3 \\
\hline C4 & $\begin{array}{l}\text { Teknologi Yang } \\
\text { Digunakan }\end{array}$ & + & 2,7 \\
\hline C5 & Harga & - & 1,4 \\
\hline
\end{tabular}

Tabel 4. Nilai Alternatif untuk masing-masing Kriteria(Matrix of responses)

\begin{tabular}{|l|l|l|l|l|l|}
\hline Kode & C1(+) & C2(-) & C3(-) & C4(+) & C5(-) \\
\hline A1 & 30 & 50 & 20 & 30 & 40 \\
\hline A2 & 30 & 50 & 40 & 50 & 40 \\
\hline A3 & 30 & 50 & 30 & 30 & 40 \\
\hline A4 & 30 & 50 & 30 & 30 & 40 \\
\hline A5 & 30 & 50 & 50 & 40 & 10 \\
\hline A6 & 30 & 50 & 20 & 30 & 30 \\
\hline
\end{tabular}

Ratio System - Menghitung Ratio

Matriks Keputusan

$\left[\begin{array}{lllll}30 & 50 & 20 & 30 & 40 \\ 30 & 50 & 40 & 50 & 40 \\ 30 & 50 & 30 & 30 & 40 \\ 30 & 50 & 30 & 30 & 40 \\ 30 & 50 & 50 & 40 & 10 \\ 30 & 50 & 20 & 30 & 30\end{array}\right]$

Hasil Matrik Normalisasi dari Matriks Keputusan Diatas :

$\left[\begin{array}{lllll}0,408 & 0,408 & 0,244 & 0,342 & 0,465 \\ 0,408 & 0,408 & 0,488 & 0,569 & 0,465 \\ 0,408 & 0,408 & 0,367 & 0,342 & 0,465 \\ 0,408 & 0,408 & 0,367 & 0,342 & 0,465 \\ 0,408 & 0,408 & 0,611 & 0,456 & 0,116 \\ 0,408 & 0,408 & 0,244 & 0,342 & 0,349\end{array}\right]$

Ratio System - Menghitung Nilai Optimasi dan Memeringkat Alternatif

Menghitung Nilai Optimasi dari masing-masing alternatif :

Tabel 5. Nilai Optimasi dan Ranking

\begin{tabular}{|l|l|l|}
\hline $\begin{array}{l}\text { Kode } \\
\text { Alternatif }\end{array}$ & $\begin{array}{l}\text { Nilai } \\
\text { Optimasi }\end{array}$ & Ranking \\
\hline A1 & 3,7684 & 5 \\
\hline A2 & 4,6985 & 1 \\
\hline A3 & 3,9283 & 3 \\
\hline A4 & 3,9283 & 4 \\
\hline A5 & 4,0647 & 2 \\
\hline A6 & 3,606 & 6 \\
\hline
\end{tabular}

2. Hasil Keputusan

Hasil dari Sistem Pendukung Keputusan dengan metode MOORA ini yaitu dipilih alternatif $y_{2}^{*}$ (SHARP AH-A5UCY) dengan Nilai Optimasi sebesar 4,6985.

\section{E. KESIMPULAN}

Metode MOORA dapat menghasilkan keputusan rekomendasi dalam hal ini yaitu untuk menentukan Penyejuk Udara terbaik berdasarakan beberapa kritera yaitu daya tahan umur AC, kapasitas, konsumsi listrik, teknologi yang digunakan dan harga yang bisa dijadikan sebagai acuan bagi konsumen 
dengan harga yang paling murah dan kualitas terbaik dari beberapa merk AC yang dijadikan sebagai alternatif pembanding. Penerapan metode moora ini menghasilkan rekomendasi berupa produk AC yang hemat biaya, harga dan memiliki kualitas terbaik.

\section{DAFTAR PUSTAKA}

[1] http://manado.tribunnews.com/2018/1 0/09/gini-penjelasan-bmkg-soalcuaca-di-indonesia-yang-semakinpanas.Tanggal Akses : 10 Oktober 2018 Pkl 09:15

[2] https://inet.detik.com/consumer/d4166589/ baru-9-persen-ac-diindonesia-pakai-inverter. Tanggal Akses : 10 Oktober 2018 Pkl 10:00

[3] Fhery Agustin, Analisis Rekomendasi Pemilihan Perangkat Penyejuk Udara Menggunakan Metode Fuzzy SAW, Seminar Nasional Informatika 2015, Universitas Potensi Utama Medan

[4] Aprina Susanti, Fitriyadi, Artoni. 2015. Model Sistem Rekomendasi Pemilihan Mesin Cuci Berbasis Fuzzy Tahani, Progresif Vol.11 No.2, ISSN : 0216-3284

[5] Nur Huzumah, Toni Arifin. 2018. Sistem Pemilihan Mesin Cuci Berdasarkan Fuzzy Tahani dan Promethee, Jurnal Informastika Vol.5 No.1, ISSN : 2355-6579

[6] https://www.arjunaelektronik.com/pan duan/panduan-membeliac/menentukan-kapasitas-ac-sesuaidaya-listrik-rumah/. Tanggal Akses : 7 November 2018 Pkl 09:00

[7] Samuel Manurung, Sistem Pendukung Keputusan Pemilihan Guru dan Pegawai Terbaik Menggunakan Metode Moora, Jurnal Simetris, Vol.9 No. 1 April 2018. ISSN : 2252-4983

[8] Nofriansyah, Dicky, Konsep Data Mining Vs Sistem Pendukung Keputusan, Deepublish, Yogyakarta, 2014.

[9] Tseng, G.H. dan Huang, J.J. 2011. Multiple Atrribute Decision Making, Methods and Applications, CRC Press. Boca Raton.
[10] Fulop, Janos. 2005. Introduction to Decision Making Methods, Hungarian Academy of Sciences.

[11]Willem Karel, Brauers M, Zavadskas EK. 2006. The MOORA method and its application to privatization in a transition economy Vol. 35 no 2 . Belgium

[12] Mandal, U. K. dan Sarkar, B. 2012. "Selection of Best Intelligent Manufacturing System (IMS) Under Fuzzy Moora Conflicting MCDM Environment". International Journal of Emerging Technology and AdvancedEngineering (IJETAE). Vol 2(9) : 301-310 